\title{
Out of the Crisis by Design
}

\author{
Maurizio Sabini
}

EDITORIAL

The scale of the COVID-19 pandemic outbreak and impact, unprecedented in modern history for about a century, urges all of us engaged in the design fields to offer contributions in order to curb, mitigate, and resolve the catastrophic situation that public health is facing worldwide as public health and environment are closely interconnected. This crisis, though, like others in the past, may also offer opportunities. The history of architecture, design and urbanism is rich of critical advancements that ended up to stay and change our lives, but ones that precisely resulted from creative reactions from public health crises. Modern architecture, for one, is an example. Corbu's prophetic visions of the early 1920s (a century ago!), while outlining a path "toward an architecture," return to resonate with fascinating timeliness:

Vast spaces with sun and air onto which all apartments open. Gardens and playgrounds at the foot of the houses. ... Richness is provided by the breadth of the layout and by the play of vegetation over the geometric canvas of the facades... Instead of laying out cities in large quadrangular blocks with narrow channels of streets... apartments should open on every side to air and light, and overlooking not the sickly trees of today's boulevards but lawns, playing fields, and luxuriant vegetations... " 1

The kind of radical thinking that marked the affirmation of Modernism as the shaping of the built environment interpreting and representing the promise of Modernity is what is also needed at this juncture as we battle our exit from the COVD-19 crisis and related emergencies. This pandemic has also exposed the inadequacies of our infrastructures, cities and human 
settlements world-wide. The social and human toll, also in terms of unequal impact of the outbreak across sectors of society, is also unprecedented. Hence, what are the lessons that we, as architects, designers and urbanists, can learn from this experience, so that, as Bill Gates had warned us in 2015, "we can be ready for the next epidemic"? ${ }^{2}$ How do we reconcile density with healthy social distancing? How can we make public transport safer? How do we re-balance priorities between public and private transportation infrastructures? What are the strategies to seek the help of healthier natural ecologies within our cities? How do we push the envelope of sustainability, at the urban and the building scale, beyond energy, to include standards for public health?

The TPJ called researchers and reflective practitioners from around the world to offer and test ideas in response to those questions.

The issue is premised by a fitting testimonial by a doctor, an environmental epidemiologist in his own merit, Dr. Raymond Richard Neutra, reflecting on the legacy of his own father Richard Neutra, a pioneer and champion for a health-driven design approach within the framework of modern architecture. The opening contribution is a speculative project for a provocative vision of "ecological arks for survival," by Alberto Francini and Fabrizio Mangiaveti, that, precisely because of its suggestive power, warrants further explorations and in-depth design research and applications. A series of articles and essays follow by framing the theme at a general level, though from different view-points: outlining an historical arc, till present day, of health-driven urbanistic strategies (Aki Ishida), discussing healthy living models in a global perspective, from New York to Lagos (Emily Moss et al.), re-envisioning the critical role of open spaces for our future cities (Ulysses Vance), and testing the power of small scale tactical urbanism within the complex system of infrastructures of three world cities such as Barcelona, Beijing and Milan (Luca M. F. Fabris et al.). The issue continues with more specific applications of analysis and creative response via health-driven design intelligence to a number of case-studies: from Detroit (Craig Griffen, on a more planning level, and Joongsub Kim, on a more sociological and place-making level), to Baltimore (Cristina C. Murphy and Carla Brisotto, with a view to a more equitable food accessibility), to Addis Ababa (Ruben Garcia Rubio and Taylor Scott, imagining more sustainable infrastructures for healthier megacities in less developed countries), to Los Angeles and its river (Nicole Lambrou, uncovering socio-environmental challenges and ecological opportunities for natural infrastructures within urban settings).

What all these studies, visions and proposals show us is that a healthier urbanism is not a new challenge and many lessons can be learned from past mistakes and successes; a healthier urbanism is possible to be achieved, but it requires thorough analyses, radical thinking and creativity; it should not be limited to an emergency agenda as a temporary reaction to a global public health crisis, but become one of the constant drivers of design research for our future, healthier world. 


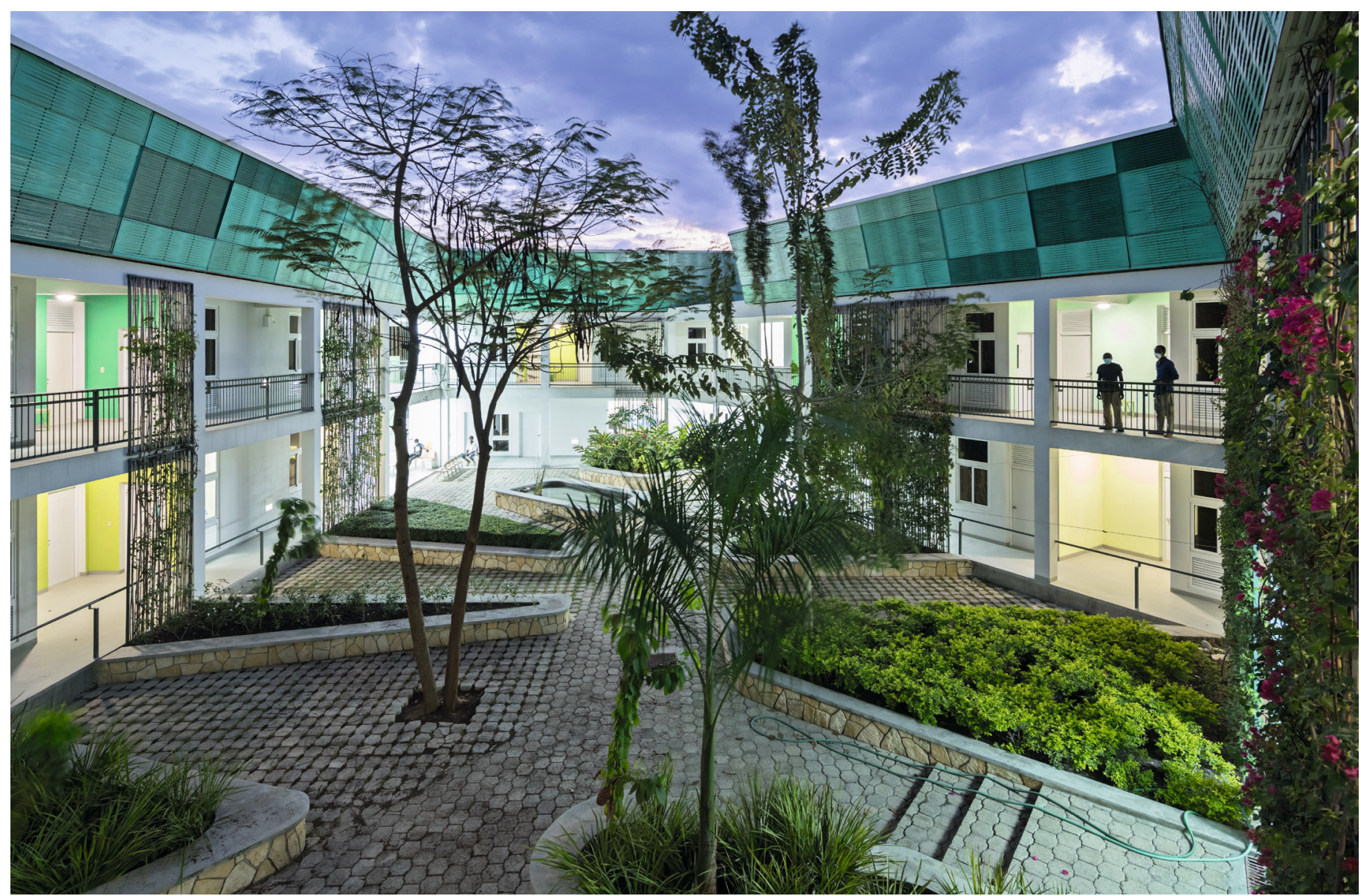

MASS Design Group, GHESKIO Tuberculosis Hospital, Port-au-Prince, Haiti, 2015. Photo (C) Iwan Baan.

\section{Notes}

1. Le Corbusier, Toward an Architecture, intr. Jean-Louis Cohen, trans. John Goodman (Los Angeles: The Getty Research Institute, 2007 (trans. from the 2nd ed., 1924), 128-29; or. ed., Vers une architecture, 1923).

2. Bill Gates, "TedTALK," March 2015: https://www.ted.com/talks/bill_gates_the_next_ outbreak_we_re_not_ready?language=it. 